\title{
Serotonin and human cognitive performance
}

Citation for published version (APA):

Schmitt, J. A. J., Wingen, M., Ramaekers, J. G., Evers, E. A. T., \& Riedel, W. J. (2006). Serotonin and human cognitive performance. Current Pharmaceutical Design, 12(20), 2473-86.

https://doi.org/10.2174/138161206777698909

Document status and date:

Published: 01/01/2006

DOI:

10.2174/138161206777698909

Document Version:

Publisher's PDF, also known as Version of record

Document license:

Taverne

Please check the document version of this publication:

- A submitted manuscript is the version of the article upon submission and before peer-review. There can be important differences between the submitted version and the official published version of record.

People interested in the research are advised to contact the author for the final version of the publication, or visit the DOI to the publisher's website.

- The final author version and the galley proof are versions of the publication after peer review.

- The final published version features the final layout of the paper including the volume, issue and page numbers.

Link to publication

\footnotetext{
General rights rights.

- You may freely distribute the URL identifying the publication in the public portal. please follow below link for the End User Agreement:

www.umlib.nl/taverne-license

Take down policy

If you believe that this document breaches copyright please contact us at:

repository@maastrichtuniversity.nl

providing details and we will investigate your claim.
}

Copyright and moral rights for the publications made accessible in the public portal are retained by the authors and/or other copyright owners and it is a condition of accessing publications that users recognise and abide by the legal requirements associated with these

- Users may download and print one copy of any publication from the public portal for the purpose of private study or research.

- You may not further distribute the material or use it for any profit-making activity or commercial gain

If the publication is distributed under the terms of Article $25 \mathrm{fa}$ of the Dutch Copyright Act, indicated by the "Taverne" license above, 
See discussions, stats, and author profiles for this publication at: https://www.researchgate.net/publication/6943885

\section{Serotonin and Human Cognitive Performance}

Article in Current Pharmaceutical Design · February 2006

DOI: 10.2174/138161206777698909 · Source: PubMed

CITATIONS

218

5 authors, including:

Jeroen A J Schmitt

Agency for Science, Technology and Research ( $A^{*}$ STAR)

55 PUBLICATIONS 2,532 CITATIONS

SEE PROFILE

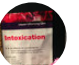

Johannes G Ramaekers

Maastricht University

311 PUBLICATIONS 8,944 CITATIONS

SEE PROFILE

Some of the authors of this publication are also working on these related projects:

EU DRUID PROJECT View project

ALICE-RAP. Work Package 11 - Deliverable 11.3. Marketing and Brain Activity View project
READS

1,545

Marleen Wingen

Centraal Bureau voor de Statistiek

30 PUBLICATIONS 791 CITATIONS

SEE PROFILE

Wim J Riedel

Maastricht University

149 PUBLICATIONS 7,250 CITATIONS

SEE PROFILE 


\title{
Serotonin and Human Cognitive Performance
}

\author{
J.A.J. Schmitt ${ }^{1,2, *}$, M. Wingen ${ }^{2}$, J.G. Ramaekers ${ }^{2}$, E.A.T. Evers ${ }^{3}$, and W.J. Riedel ${ }^{2,4,5}$
}

${ }^{1}$ Nestlé Research Center, Nutrition and Health Department, Lausanne, Switzerland; ${ }^{2}$ Experimental Psychopharmacology Unit, Dept of Neurocognition, Faculty of Psychology, Maastricht University, The Netherlands; ${ }^{3}$ Dept. Psychiatry \& Neuropsychology, Brain \& Behaviour Institute, Maastricht University, The Netherlands; ${ }^{4}$ Psychiatry Discovery Medicine, GlaxoSmithKline R\&D, Cambridge, United Kingdom and ${ }^{5}$ Department of Psychiatry, University of Cambridge, United Kingdom

\begin{abstract}
In the past decade, experimental studies involving healthy human volunteers have revealed that manipulations of the central serotonin (5-HT) system can produce quite specific changes in cognitive functioning, independent of overt mood changes. Reduced 5-HT turnover is consistently associated with impaired long-term memory functioning. Low 5HT function may also impair cognitive flexibility and improve focused attention. On the other hand, stimulation of central 5-HT has repeatedly been found to impair performance in a true vigilance task. Currently, there is little evidence for mirrored cognitive changes due to opposite 5-HT manipulations in healthy volunteers. Given the mounting evidence for a role of 5-HT in human cognition, reduced 5-HT function could be directly linked to cognitive disturbances in certain conditions, such as in depression and Alzheimer's Disease (AD). There is evidence that stimulating (i.e. normalizing) 5HT activity in depression may have specific beneficial effects on cognition, independent of a general relief of depressive symptoms, but this premise needs to be confirmed by larger-scale clinical studies. Recently, a potential role of 5-HT in the cognitive symptoms in AD has been identified, but there is insufficient data to evaluate the effects of 5-HT stimulation on cognitive symptoms in AD. It is concluded that serotonin is a potential target for pharmacological cognition enhancement, particularly for restoration of impaired cognitive performance due to 5-HT dysfunction. Further differentiation of the role of 5-HT in normal and disturbed cognition and evaluation of the effects of 5-HT manipulations in various populations is required to establish the full potential of 5-HT drugs as cognition enhancers.
\end{abstract}

Key Words: Serotonin, memory, cognition, depression, Alzheimer’s Disease, cognition enhancement.

\section{INTRODUCTION}

Serotonin (5-HT) has long been implicated in a wide range of behavioural functions, specifically in mood regulation, aggression and impulsivity. Serotonergic disturbances are linked to a variety of psychopathological conditions, the most prominent being depression, bipolar disorder and obsessive compulsive disorder [1]. In the past decade, experimental studies with animals and humans have revealed that 5-HT may also play an important role in normal and disturbed cognitive functioning. The premise that $5-\mathrm{HT}$ is involved in cognitive functions has important implications. First, it broadens our understanding the origin of cognitive deficits that are associated with certain conditions. For example, sub-optimal 5-HT activity may be responsible for at least part of the cognitive deficits seen in depression [2]. Low 5-HT has recently been related to cognitive deficits seen in Alzheimer's Disease [3-5] and may even contribute to age-related cognitive decline [6]. Even in healthy women with premenstrual complaints, cognitive deficits have been related to serotonergic disturbances [7]. Secondly, such insights provide the basis for the development of treatment strategies for such conditions. Currently, the serotonergic system is considered a promising target for cognition of

\footnotetext{
*Address correspondence to this author at the Nutrition and Health Department, Nestlé Research Center, PO Box 44, CH-1000 Lausanne, Switzerland; Tel: +41 21785 8167; Fax: +41 21785 8544;

E-mail: jeroen.schmitt@rdls.nestle.com
}

cognition helps predict and possibly avoid cognitive side effects of drugs affecting the 5-HT system [10].

Several excellent reviews are available on animal studies on serotonergic modulation of cognition [11-15]. Despite recent developments and insights, however, an extensive overview focusing on human studies in this field is not available. The aim of the current review is to discuss the evidence for a role of 5-HT in human cognitive functions; identify specific human cognitive functions that may be mediated by 5 -HT; and to explore the conditions under which manipulations of central serotonergic activity may enhance cognitive performance in human subjects. For the purpose of this review, we will focus on the results from psychopharmacological manipulations in either healthy volunteers or selected patient groups. Although occasionally results from animal studies will be briefly addressed to provide supplementary information and identify possible neurobiological mechanisms, an extensive discussion of the animal data on 5-HT and cognition is beyond the scope of this paper. For this, the reader is referred to the aforementioned review papers.

In humans, several psychopharmacological approaches can be employed to study 5-HT function in relation to cognition. In recent years, acute tryptophan depletion (ATD) has gained popularity as a method to temporarily lower 5HT activity in the human brain. The method is based on reducing the availability of L-tryptophan (TRP), the only precursor for 5-HT, in the brain. In short, ATD involves oral 
administration of an amino acid suspension without TRP, which reduces TRP transport into the brain by increasing competition for active transport sites across the blood-brain barrier. ATD leads to marked reductions of brain TRP, 5-HT and 5-HIAA (for reviews see [16, 17]). For example, five hours after intake of the ATD mixture, the alfa-methyl[11C]-tryptophan labeled method of estimating 5-HT synthesis rate yielded values across various regions throughout the brain suggesting that 5 -HT synthesis rate was reduced by $\sim 87 \%$ and $\sim 97 \%$ in healthy men and women, respectively [18]. In rats, ATD reduces spontaneous hippocampal 5-HT release by approximately $40 \%$ [19]. In a similar fashion, increasing brain TRP availability through TRP loading can be used to stimulate central 5-HT synthesis [20, 21]. A maximal increase in brain 5-HT synthesis of $\sim 100 \%$ appears to be achieved after a $3 \mathrm{~g}$ oral TRP load [22, 23].

Quite a number of human studies have assessed cognitive changes after acute or sub-chronic administration of various medicinal drugs that stimulate 5-HT activity throughout brain. These are predominantly selective serotonin reuptake inhibitors (SSRIs) and various tricyclic antidepressants (TCAs), which increase 5-HT neurotransmission by blocking the reuptake of 5-HT into the presynaptic neuron and are widely prescribed as antidepressants. Their cognitive effects have been investigated in both healthy volunteers as well as various patient groups, particularly depressed patients. However, these studies are often clinical trials of antidepressant treatment efficacy in patients in which assessment of cognitive (side) effects is a secondary goal at most. Other studies were designed as head-to-head comparisons of cognitive side effects of competing drugs in healthy volunteers. Because of lack of specificity for the serotonergic system, TCA trials are less suitable to study 5HT effects on cognition. Their anticholinergic, antihistaminergic, antidopaminergic and/or antinoradrenergic actions are known to adversely affect cognition [24] and hence obscure any 5-HT-related changes. For this reason, this review will focus on studies involving SSRIs, which lack significant affinities for non-serotonergic neurotransmitter systems, to evaluate the cognitive effects of global 5-HT stimulation. In addition to the aforementioned methods to alter whole brain 5-HT activity, a number of 5-HT receptor agonists and antagonists with varying selectivity are available for human research. However, these compounds have only sporadically been used in human cognitive research. This is unfortunate, as they may provide vital information regarding 5-HT receptor subtypes that are involved in specific human cognitive domains. Finally, the prolonged use of MDMA (3,4-methylenedioxymethamphetamine; ecstasy) is according to some authors associated with quite selective neurotoxic damage to 5-HT neurones in animal experiments [25]. Hence, assessment of the cognitive changes in frequent MDMA users may be used to provide indirect evidence on the role of 5-HT in human cognition. Although acute MDMA intake also invokes potent stimulatory effects on 5HT neurotransmission, additional pharmacodynamic properties of MDMA, most notably those pertaining to the dopamine (DA) system [26], renders MDMA less suitable for examination of specific 5-HT mechanisms.

The evidence for a role of 5-HT in human cognition will be discussed in two sections, one dealing with healthy vol- unteer studies, the other with studies in selected (clinical) populations. The distinction is based on the premise that the cognitive effects of various 5-HT manipulations may vary according to baseline central 5-HT activity. In several conditions, e.g. depression, and possibly also Alzheimer's disease and normal aging, both 5-HT hypofunction and cognitive decline is observed. At this point, the causal relation between a compromised central 5-HT system and the observed cognitive deficits in these and other conditions has not been clearly established, but there is increasing evidence that low 5-HT is at least partially linked to the cognitive problems. Hence, these populations may specifically benefit from pro-serotonergic pharmacological therapies that shift central 5-HT neurotransmission towards a more optimal level, thus restoring cognitive function. By contrast, in healthy volunteers, no performance deficits due to a compromised 5-HT system are to be expected. As they already operate close to their optimal cognitive performance level, cognition enhancement is generally difficult to achieve, by any means. Possibly, stimulation of the 5-HT system in this group may even result in diminished performance, if optimal 5-HT modulation is disrupted. As such, assessing the cognitive sequelae of altered central 5-HT levels in healthy volunteers is a valuable method to identify the fundamental role of 5-HT in cognition, providing leads for investigating possible serotonergic mechanisms underlying impaired cognition in specific clinical populations, and ultimately providing the rationale for serotonergic treatment options.

\section{SEROTONIN AND HUMAN COGNITION: EVI- DENCE FROM HEALTHY VOLUNTEER STUDIES}

Recent findings from psychopharmacological studies with healthy volunteers have identified a number of cognitive domains that appear to be sensitive to changes in 5-HT neurotransmission in the brain. The most consistent effects relate to long-term memory functions, certain attentional functions, notably focused and sustained attention, and specific executive functions that mediate behavioural adaptations to changing environmental demands: a function referred to as cognitive flexibility. In the following section, the evidence for 5-HT involvement in these functions from experiments with healthy human volunteers is reviewed.

\subsection{Serotonin and Human Memory Functions}

Memory is a multifaceted cognitive function relating to the acquisition, storage and preservation of information for short and longer time periods, and the subsequent retrieval of this information. Numerous memory tests are available, varying in terms of the types of information, temporal characteristics and specific processes that are targeted. List learning paradigms are often used to test various aspects of declarative memory (memory for facts). Such tests typically consist of one or more acquisition trials in which information is presented, followed by recall and recognition trials to assess retrieval and storage, respectively. Varying the time interval between presentation and assessment allows for a differentiation between short- and long-term memory functioning.

The serotonergic system appears to be involved in specific human memory processes. The perhaps most compel- 
ling evidence for this was obtained in a number of experiments in which ATD was used to lower central serotonergic activity in healthy volunteers. These studies demonstrated that lowering of serotonergic activity is associated with a quite specific impairment of long-term memory performance [2]. In one of the initial experiments, Riedel et al. [27] showed that ATD reduced the ability to actively recall, as well as recognize, words from a previously presented word list. The effect was only apparent after a 30-minute delay between presentation and assessment, but not when word recall was assessed immediately after presentation. This pattern lead the investigators to the conclusion that consolidation of new information into long-term memory was compromised by a reduction of central 5-HT activity, but that short-term memory functions appear to be spared. Several studies have subsequently confirmed the notion that 5-HT is specifically involved in long-term memory functioning. ATD was found to specifically reduce delayed recall and/or delayed recognition of visually presented words [28-32], spoken words [33], pictures [31] and even abstract figures [34], whereas two studies failed to detect ATD-induced changes in memory for words $[35,36]$. The authors of the latter study suggest that the results may have been hampered by modest levels of tryptophan depletion. Overall, results seem to indicate that ATD-induced memory impairment occurs independent of the nature of the stimuli and suggest that 5-HT modulates long-term memory processes at a fundamental level. The specificity of this effect for the depletion of tryptophan was demonstrated in two studies where the memory consolidation deficit was found in the ATD condition but not when other amino acids, lysine [37] and tyrosine/phenylalanine [30] respectively, were depleted within the same group of volunteers. Furthermore, it was demonstrated that ATD does not affect long-term memory retrieval or recognition when the depletion is induced after learning and consolidation of a word list [29]. Event related potential (ERP) recordings further showed that impaired long-term memory recall for words after ATD occurred without changes in the magnitude or topography of the neural correlates of retrieval functions [33]. These results suggest that impaired storage and/or consolidation of new information, rather than the failure to access and retrieve information, underlies poor failure long-term memory performance after 5-HT depletion.

The results emerging from ATD studies indicate that reduced long-term memory performance is not likely to be attributable to consistent changes in perceptual functions, information processing, attention or executive functions [27, $29,30,38,39]$. In fact, there is some indication that some attentional functions, i.e. selective attention (see below), and memory-related executive functions, i.e. strategy driven retrieval from semantic memory (word fluency), may benefit from a reduction of 5-HT neurotransmission [29]. Also, the absence of evident changes in self-reported mood ratings of healthy volunteers following ATD [2, 20, 40] suggests that diminished memory function is not mediated by mood changes. A detailed analysis of the long-term memory impairment following ATD, however, revealed that recall of words with a positive and neutral affective valence was specifically impaired, whereas recall of negative words was unaffected [41]. The authors conclude that 5-HT depletion shifts affective memory bias towards words with a negative affective valence. Supporting this notion, recent data show that ATD was associated with a specific decrement in memory for positively loaded words [28]. The results are indicative of a mood congruent memory bias caused by a lowering of mood and suggest an interaction between subtle mood effects and memory effects induced by low 5-HT activity.

In contrast with the quite consistent findings on 5-HT depletion and memory impairment, the studies on the effects of 5-HT stimulation on memory functions in healthy volunteers are scarce and have yielded rather inconsistent results. No changes in long or short-term memory performance were seen after $50 \mathrm{mg}$ acute [42] or 50-100 $\mathrm{mg}$ subchronic [43, 44] administration of the SSRI sertraline in healthy volunteers. Citalopram administration has been associated with decreased long-term memory performance in healthy middle-aged subjects. After 14 days of treatment with citalopram: $20 \mathrm{mg}$ on days $1-7 ; 40 \mathrm{mg}$ on days $8-14$, subjects reproduced 1.5 words less $(5 \%)$ at delayed recall [45]. Impairment of delayed word recall was also found after subchronic administration of $20-40 \mathrm{mg}$ paroxetine in healthy middle-aged subjects [43]. Memory function, particularly long-term memory retrieval and storage, was impaired following intravenous administration of $7 \mathrm{~g}$ TRP [46]. However, the relatively high dose of TRP had marked sedative effects, probably due to the conversion of TRP to melatonin, as was apparent from subjective rating scales and spontaneous reported side effects. Moreover, sedation was positively correlated with memory performance, suggesting that the observed memory effect was primarily mediated by melatonin accumulation and possibly, to some extent, by sedative effects of 5-HT stimulation itself (see 2.2.2). Finally, memory-enhancing effects of SSRIs have also been reported. An acute intravenous administration of $10 \mathrm{mg}$ of the selective serotonin reuptake inhibitor (SSRI) citalopram in healthy volunteers was shown to facilitate verbal memory consolidation [47]. After subchronic administration of the SSRI sertraline in healthy elderly subjects, sertraline plasma levels were correlated positively with short-term memory scores on day 7 (low dose: $50 \mathrm{mg}$ ) and long-term memory scores on day 21 (high dose: $150 \mathrm{mg}$ ), while no correlation with memory was found on day 14 (intermediate dose: $100 \mathrm{mg}$ ) [48]. A study of the acute effects of $10 \mathrm{mg}$ ipsapirone, a 5$\mathrm{HT}_{1 \mathrm{~A}}$ agonist, and $0.5 \mathrm{mg} / \mathrm{kg} \mathrm{m}-\mathrm{CPP}$ (metachlorophenylpiperazine), a $5-\mathrm{HT}_{2 \mathrm{C}}$ agonist, showed that ipsapirone impaired immediate recall in healthy volunteers [49].

Data from 5-HT depletion studies provide ample evidence for a role of the central serotonergic system in longterm memory functioning. It seems that increasing 5-HT activity in healthy volunteers, however, does not necessarily lead to memory improvement. In fact, some findings suggest that overstimulation of the 5-HT system actually induces memory impairment. The absence of consistent beneficial effects of 5-HT stimulation may indicate that in healthy volunteers, under normal conditions, the level of central 5HT activity is not a limiting factor for optimal memory functioning. From the current data, 5-HT manipulations do not seem a particular viable method to enhance memory in healthy subjects, although reports of improved memory following 5-HT stimulation certainly merit further investigation. 


\subsection{Serotonin and Human Attention Functions}

\subsubsection{Focused Attention}

Focused attention refers to the ability to attend a relevant stimulus or stimulus attribute while ignoring irrelevant information. In focussed attention tasks a predefined informational cue, indicating the required response, is accompanied by distracting information, which causes interference. A classic and often used test of focused attention is the Stroop Colour Word Test [50], in which subjects have to ignore the content of a series of printed colour names and name the incongruent ink colours (e.g. "yellow" printed in blue ink). Interference can also be introduced in flanker tasks [51] by simultaneous presentation of distracting information in proximity of the target stimulus, e.g. a central arrow that indicates the required response is flanked by arrows that point in the opposite direction. Another example of a focused attention task is the shadowing condition of the dichotic listening task [52], in which series of numbers spoken in one ear have to be processed while ignoring simultaneously spoken numbers in the other ear.

Data from several ATD experiments indicate a putative role of 5-HT in the modulation of focused attention. In a healthy volunteer study, ATD was found to reduce interference in a Stroop Colour Word Test and increase performance on the focussed attention component of the dichotic listening task [29]. These findings are in line with previous ATD studies reporting decreased interference in the Stroop test [32] and speeded responses to incompatible stimuli (e.g. the word "left" presented at the right side of the screen) after ATD [53]. The positive effects of ATD on Stroop and dichotic listening performance could not be replicated in a subsequent study, although the data tended to show a similar pattern [31]. The authors argued that the heterogeneity of their study population, in terms of age and psychiatric family loading, may have lead to reduced sensitivity. Lack of ATD effects on Stroop performance have also been reported in two other studies $[38,54]$. A recent finding, however, of a dose-related increase in performance on the Stroop test in a study comparing the effects of two levels of ATD in depressed patients provides strong evidence for 5-HT involvement in focused attention [55]. The role of 5-HT in focused attention is further substantiated by EEG (electroencephalography) and MEG (magnetoencephalography) measures in healthy volunteers after ATD. Both EEG and MEG correlates of auditory attention (mismatch negativity, $\mathrm{N} 2 \mathrm{~b}$ and N2 wave) suggested that ATD decreased involuntary attention shifting to task-irrelevant sound changes and thus modulated resource allocation to the task-relevant activity [56].

In healthy volunteers, there is no clear evidence that 5HT stimulation influences measures of focused attention, although it must be noted that only a few studies have addressed this issue. Performance on the Stroop test was unaffected by 14-15 days of administration of 20-40 mg paroxetine [57-59] and 50-100 mg sertraline [58]. No changes in performance on a dichotic listening task, in an identical version that was shown to be sensitive to ATD, were found following sub-chronic administration of $50-100 \mathrm{mg}$ sertraline and 20-40 mg paroxetine [58]. A $7 \mathrm{~g}$ intravenous TRP challenge to stimulate 5 -HT neurotransmission resulted in diminished speed of responding to incompatible stimuli in a left-right task TRP [46], in line with the effects of ATD on focused attention. However, the effect was only observed in those subjects with a first degree relative with bipolar disorder. Furthermore, the effect did not extend to other tests of focused attention in the study, i.e. the Stroop test and dichotic listening.

\subsubsection{Sustained Attention (Vigilance)}

Sustained attention is the ability to direct and focus cognitive activity or alertness on specific stimuli over a prolonged period of time. In tests of sustained attention or vigilance stimuli are usually intermittent, unpredictable and infrequent. The prototypical vigilance task is the Mackworth Clock task [60]. This task was developed during World War II to simulate radar monitoring operations. A computer screen displays a circular arrangement of dots simulating the second marks on a clock. Dots are briefly illuminated in clockwise rotation. At irregular intervals a "double jump" occurs by skipping one of the dots in the normal sequence. These are the signals that an observer has to detect and respond to. It has been shown that vigilance performance declines steeply as a function of time on task [60].

Augmentation of 5-HT neurotransmission has been shown to impair human vigilance performance, i.e. the ability to remain alert for prolonged periods of time. Ramaekers et al. [61] compared the acute and subchronic effects of fluoxetine $20 \mathrm{mg}$ on sustained attention to those of placebo in a double-blind, cross-over study involving 18 healthy volunteers. Sustained attention was assessed using the Mackworth Clock paradigm [60] on days 1, 8 and 22 of treatment. A reduction in sustained attention was observed throughout the fluoxetine treatment period. The selective impairing effects on vigilance and sustained attention have also been observed following two weeks of administration of incremental dose regimens of venlafaxine $(75-150 \mathrm{mg})$ to healthy volunteers. Little effect of venlafaxine on sustained attention was seen on the first day of treatment but the effect increased to become significant after one week of treatment. Subjects seemed to notice venlafaxine's effect on vigilance as they subjectively rated their alertness less as compared to placebo. Single and repeated doses of paroxetine $30 \mathrm{mg}$ did not affect vigilance performance as compared to placebo in healthy volunteers [62]. However in this study maprotiline $100 \mathrm{mg}$ failed to affect vigilance performance also, even though this drug is known to produce drowsiness. Deyen et al. [62] did not reveal any task parameters relevant to an operational Mackworth clock paradigm but their vigilance data suggests that their version may not have been sensitive enough to assess drug-induced changes. Schmitt et al. [58] on the other hand did report a paroxetine induced vigilance decrement. They compared the effects of subchronic treatment with sertraline $(50-100 \mathrm{mg})$ and paroxetine $(20-40 \mathrm{mg})$ on sustained attention in a placebo controlled study in 21 healthy volunteers. Paroxetine significantly reduced performance on the Mackworth Clock task, i.e. it decreased the number of correct detections and increased mean reaction time for correct detections. In contrast, sertraline did not reduce the number of correct detections and decreased mean reaction time. Similar results were reported in a placebo controlled study by Riedel et al. [45]. They found that cita- 
lopram impaired vigilance performance in healthy volunteers during the first week of treatment with $20 \mathrm{mg}$ and during the second week of treatment with $40 \mathrm{mg}$ daily. In contrast, no vigilance impairment was found during sertraline $(50-100 \mathrm{mg})$ treatment. The magnitude of citalopram induced impairment in the Mackworth Clock task was comparable to that previously observed for fluoxetine, venlafaxine and paroxetine [58, 61, 63]. Edgar et al. [64] assessed vigilance performance in 2 groups of healthy volunteers who received 16 days of treatment with escitalopram or sertraline. The Mackworth Clock Test was administered at baseline and on day 16 at 2 and 4 hrs post dosing. Relative to baseline escitalopram decreased vigilance accuracy, but only at 2 hrs post dosing. Harmer et al. [47] failed to measure any affect of citalopram on sustained attention while using another vigilance paradigm: i.e. Rapid Digit Information Processing. It is unclear however whether this paradigm measures the same aspects of vigilance as the Mackworth Clock Test.

Thus, sertraline is the only SSRI studied so far with no detrimental effects on vigilance. It has been suggested that the latter may be due to the fact that sertraline also possesses an ancillary mechanism that facilitates cortical arousal; i.e. blockade of DA reuptake. In such case vigilance impairment following 5HT stimulation may be counteracted by the vigilance promoting effects of DA stimulation [58].

Studies employing the Mackworth Clock paradigm thus all seem to point out that enhancing 5-HT in normal individuals consistently impairs vigilance. The mechanism underlying this effect however has not been fully elucidated. A reduction in noradrenergic (NA) activity does not seem to play a major role as simultaneous enhancement of NA with 5-HT by venlafaxine was previously shown not to counteract the vigilance decrement [63]. Similarly, decreased catecholamine availability after tyrosine/phenylalaline depletion did not affect performance of healthy volunteers in a digit-vigilance task [30]. Animal studies have also indicated that NA is not specifically associated with the maintenance of vigilance $[65,66]$, but is more likely to control phasic arousal and hence may be related only when a sensory pathway habituation type of vigilance decrement is at stake. DA on the other hand has been associated with tonic arousal and readiness to respond $[67,68]$. Stimulation of DA transmission by amphetamine and methylphenidate has been shown to improve vigilance performance [69]. Vigilance impairment produced by SSRIs may involve both 5HT and DA neural circuits. It is interesting in this context that simultaneous depletion of 5HT and catecholamines did impair sustained attention of healthy volunteers in a digit-vigilance task [70], whereas selective depletion of 5HT and catecholamines did not [30]. It has been shown that 5HT projections from the raphe nucleus exert a tonic inhibitory influence over the mesocortical, nigrostriatal and mesolimbic DA systems. Thus augmentation of 5HT can be predicted to further inhibit DA transmission in DA pathways [58].

Several researchers have claimed that SSRIs can increase general CNS (Central Nervous System) arousal and attention [71]. This claim was generally based on the notion that SSRIs are capable of increasing the critical flicker fusion (CFF) threshold in healthy volunteers. CFF is a task that requires subjects to discriminate flicker from fusion in a set of light emitting diodes held in foveal fixation. The psychological functions that are being measured with CFF however have never been truly established. In general, drug induced decrements in CFF threshold are believed to reflect sedative aspects from a particular compound, whereas elevation of $\mathrm{CFF}$ threshold might indicate the opposite: i.e. activation. If true, data demonstrating elevated CFF thresholds after SSRIs administration could be taken to support the notion that these drugs improve (sustained) attention. However it has also been argued that a rise in CFF threshold may also result from mydriasis produced by SSRIs rather than a change in arousal [61]. Pupil diameter is an important determinant of CFF threshold and several studies have shown that serotonergic drugs may alter pupil size. More in particular it has been shown that SSRIs may cause a $2 \mathrm{~mm}$ increase in pupil size after single and repeated doses $[62,72-$ 75]. It is noteworthy in this respect that all of the studies reporting SSRI induced elevation of CFF threshold failed to control pupil size as a possible confounder, and that investigators that did control pupil diameter while measuring the effects of SSRIs on CFF did not report any significant elevations in CFF threshold [61, 75]. Only Mattilla et al. [76] reported a slight $\mathrm{CFF}$ threshold elevation from baseline following the administration of an SSRI (sertraline 50mg) in an CFF paradigm controlling for pupil size. However, the authors believed that this finding was invalid as it was confounded by irregular baseline deviations. When compared directly to placebo, no significant change in CFF was reported following administration of sertraline. Thus, studies showing SSRI induced elevations in CFF threshold do not necessarily contradict with studies showing that SSRIs decrease vigilance or sustained attention. CFF data should always be interpreted with caution, particularly when confounding factors such pupil size are uncontrolled for.

\subsection{Serotonin and Cognitive Flexibility}

Cognitive flexibility refers to the ability to adapt ongoing behaviour to changes in reinforcement. It is a multi component process, involving several cognitive sub-processes such as feedback processing, behavioural adaptation, learning of new stimulus-reward associations and inhibition of the previously stimulus-reward associations (response inhibition). Tasks measuring cognitive flexibility include reversal learning tasks, decision making tasks or gambling tasks, the intra dimensional/ extra dimensional shift (ID/ED) task, and the Wisconsin Card Sorting Task (WCST). Typically, these tasks require the subjects to choose the appropriate response, and adjust their response strategy based on the feedback or cues they receive (correct/incorrect, reward/punishment, probabilities). Especially the orbitofrontal and cingulate cortices have been associated with cognitive flexibility [7783]. Neuroimaging studies have implicated these brain regions in various cognitive processes that are important for flexible behaviour, including cognitive processing of affective meaning and reward, and inhibitory control (see [80, 84, 85]).

In a typical reversal learning task the subject has to choose between two stimuli that are presented simultaneously. The assignment is to identify the correct or most profitable stimulus based on the feedback that is given after 
each response. Once the correct association is learned, the reinforcement rules are reversed the subject has to adjust its responding to the new stimulus reward association (reversal shift). Several animal studies have implicated 5-HT in reversal learning (see [86, 87]). In healthy human volunteers, ATD impaired the ability to perform a reversal shift in an ID/ED task, as was apparent from an increase in erroneous responses after a reversal shift $[39,88]$. Impaired performance after ATD was also observed in a probabilistic reversal learning task, although deficits were observed for speed, rather than accuracy [85]. In a recent fMRI study [89], ATD did not affect behavioural indices of reversal learning, but increased activation in the dorsomedial PFC after ATD was found when subject adapted their behaviour after a reversal. There was a trend that the increased activation in the dorsomedial PFC extended to all the events where negative feedback was received. It was suggested that decreased 5HT may impair cognitive flexibility by increasing the sensitivity for negative feedback. Lack of effects of ATD on reversal learning, as measured by an ID/ED task [35], WCST [35, 38] and a probabilistic reversal learning task involving multiple reversal shifts [90], have also been reported. While the apparent inconsistencies may be attributed to methodological issues, i.e. small sample size [85], timing of the post-treatment assessments [90] and modest levels of tryptophan depletion [35], it is clear that further research is required to confirm and specify the role of 5-HT in reversal learning.

The ability to make decisions that are most favourable in term of reward, and to adjust choices to varying conditions of potential reward and punishment, has also been associated with 5-HT. Decision making tasks assess the quality and speed of choices that a subject makes under various conditions of potential gains or losses and associated chances of winning or losing. ATD tended to increase deliberation times, i.e. reduced the speed of decision making, particularly when probabilities of making the correct choice were higher. Furthermore, quality of decision making, i.e. choosing the most likely of the two response options, was reduced. ATD did not affect risk-taking, i.e. the size of the bets that subjects placed on a particular response, or impulsivity in the selection of the bets [91]. In subsequent study [84] it was shown altered decision making after ATD may be mediated by changes in reward processing. More specifically, ATD was found to attenuate the subjects' ability to discriminate between different magnitudes of expected gains. Processing of punishment cues (discrimination between small and large losses) or probability cues (discrimination between low and high probability of winning) was not affected by ATD. The authors propose that complex interactions between 5-HT and mesolimbic DA system may underlie the observed changes in affective processing that is associated with the orbitofrontal cortex. In contrast, Anderson et al. [92] failed to detect any ATD-induced changes in decision making in a gambling task in which probabilities of winning and potential gain were manipulated. As was also noted by the authors, the parallel group design and modest sample sizes (15 ATD versus 13 placebo subjects) probably limited the study's statistical power.

Currently, there are no reports on the effects of 5-HT stimulation on cognitive flexibility in healthy volunteers.

\section{CLINICAL ASPECTS}

\subsection{Depression, Serotonin and Cognition}

Impaired cognitive function is one of the key features of a depressive disorder. The cognitive deficits that are associated with a depressive episode were initially thought to be secondary symptoms, mediated by lowered mood, abnormal sleep, loss of interest or motivational deficits. These factors may certainly contribute to abnormal cognitive functioning in depression, however, it has now become clear that cognitive impairment is one of the core symptoms of depression and may occur independent of mood changes.

A depressive episode is often accompanied by extensive cognitive impairment across a wide range of cognitive domains. Impairment of long-term memory functioning, particularly impairment of encoding and retrieval, is frequently and quite consistently observed in depression [93-97]. In addition, attention deficits [98, 99] and impairment of executive functions, for example difficulties on measures of verbal fluency, attentional set-shifting and cognitive flexibility, are reported [96, 100-108]. Given that central serotonergic dysfunction is considered to be one of the neuronal substrates of depression [109], one could speculate at least part of the observed cognitive deficits are directly attributable to diminished brain 5-HT neurotransmission. It is particularly noteworthy that the observed deficiencies in memory encoding and/or consolidation during depression are highly comparable to the memory effects that are seen following ATD in healthy volunteers [2]. Similarly, reduced cognitive flexibility in depression seems to be in line with ATD-induced impairment of cognitive flexibility in healthy volunteers. It must be noted, however, that depression is also associated with deficits in central catecholaminergic (i.e. NA and DA) activity $[110,111]$ neuroendocrine abnormalities, (e.g. cortisol hypersecretion) $[112,113]$ and immunological changes $[114,115]$. It is therefore likely that the pattern of depressive symptoms, including the cognitive changes, are the result of a complex interplay between various neurobiological, neuroendocrine and immunological factors.

Many antidepressant drugs stimulate serotonergic neurotransmission by either blocking the reuptake of 5-HT into the presynaptic neuron or inhibiting the enzyme responsible for the degradation of 5-HT (monoamine oxidase). The most obvious and straightforward approach to gain insight in the role of 5-HT in cognitive deficits in depression is to evaluate the cognitive effects of treatment of depressed patients with pro-serotonergic antidepressants. Successful antidepressant treatment alleviates depressive symptoms and is generally associated with improvement of cognitive performance. Clinical improvement and enhanced memory performance was observed after six weeks of treatment with fluoxetine in depressed patients [116]. In elderly depressed patients, improvement of short- and long-term memory functions, visuospatial capabilities, arousal measures, and psychomotor speed was observed after 6 weeks administration of fluoxetine [117, 118]. Similarly, in elderly depressed patients, twelve weeks of treatment with sertraline reduced depression symptoms and improved short- and long-term memory function $[119,120]$. Also in elderly depressed patients, 12 weeks treatment with fluoxetine or sertraline im- 
proved clinical ratings, short- and long-term memory function and performance on the digit symbol substitution test [121-123]. It is worth mentioning that in those studies in which the effects of non-selective antidepressants were also assessed, notably mianserin [117], nortriptyline [119-121], imipramine [124] or amitriptyline [116], these drugs generally had comparable efficacy in terms of the therapeutic effect, but produced significantly less cognitive improvement or in some cases cognitive deterioration. These findings highlight the unfavourable cognitive side effects produced by anticholinergic, antinoradrenergic and antihistaminergic drug actions.

A major methodological caveat in the aforementioned clinical trials is the absence of a control condition. Cognitive performance is known to improve with repeated assessments due to practice effects, procedural learning and familiarity with the testing protocols, leading to reduced anxiety. The importance of a control group is illustrated by a study by Nebes et al. [125]. In this study, improvement of cognitive performance was observed following 12 weeks of treatment with paroxetine and nortriptyline in elderly depressed patients. However, a similar improvement of cognitive performance was observed in a healthy matched control group that underwent an identical study procedure (except for drug administration). The results could not be explained by treatment response, benzodiazepine co-medication, age of depression onset, or by co-existence of early dementia. Consequently, it was concluded that there was also no evidence for nortriptyline or paroxetine having an effect on cognition in elderly depressed patients. Others did find that nortriptyline and paroxetine treatment improved cognitive performance in elderly depressed patients compared to a healthy control group, although the effect was modest and limited to those subjects that were modestly to severely cognitive impaired at baseline [126]. Sertraline or desipramine treatment did not significantly alter cognitive performance (reaction time, DSST, trail making) in depressed elderly patients, when compared to placebo treatment. However, clinical efficacy also did not differ between treatment groups and placebo, according to the authors, due to modest sample sizes, mild to moderate severity of depression, and a high placebo response. In another study, depressed patients, when compared to a healthy control group, showed improved performance on a continuous performance task, along with clinical improvement, following 4 weeks of fluvoxamine administration [124]. In a group of depressed inpatients receiving fluoxetine, performance on a series of tests assessing fine motor skills was markedly improved after 5 weeks of treatment, compared to healthy controls undergoing the same assessments [127]. Overall, these findings suggest that cognition does tend to improve with successful antidepressant therapy, but without ample control for spontaneous changes in performance there is a risk of overestimating the actual cognitive effect of antidepressant treatment.

A second important issue is whether or not cognitive improvement after serotonergic antidepressant treatment is a direct effect of enhanced 5-HT neurotransmission or the secondary result of alleviation of the depressive illness in general, e.g. removal of mood, motivational and sleep abnormalities. Mixed results were obtained when clinical im- provement was correlated with improvement of overall cognitive performance (combined changes in memory and DSST scores) following 3 months of nortriptyline, sertraline, or fluoxetine treatment. While significant correlations were found for patients treated with sertraline and, albeit weaker, for nortriptyline, no correlation was found in patients treated with fluoxetine. Thus, although cognitive improvement may be linked to clinical efficacy, this does not seem to be a prerequisite. The authors suggested that both a direct pharmacological effect, i.e. 5-HT stimulation, as well as improvement of depression may affect cognition in depressed patients [121]. Also, no correlation between improvement of clinical depression scales and improved performance on a continuous performance test could be found following 4 weeks of imipramine or fluvoxamine treatment [124]. There is some evidence that 5-HT stimulation may indeed improve cognition directly, independent of relieve of other depressive symptoms. After 6 weeks of trazodone treatment, clinical remission and improved verbal long-term memory function (in spite of trazodone's sedating effects) was observed in a group of middle-aged depressed patients. In the ensuing placebo washout period of one week, memory performance reverted to baseline levels while depression ratings remained below depression threshold. Thus, memory function appeared to fluctuate mainly as a function of 5-HT activity, rather than depressive symptomatology [128]. In another study, the noradrenergic antidepressant desipramine and the SSRI fluoxetine were found to be equally effective in terms of their clinical effects. Improvement of memory, however, was only apparent with the serotonergic antidepressant fluoxetine. This does not only suggests a dissociation between clinical response and memory improvement, but is also in keeping with the specific role of 5-HT in memory processes [129]. One study has investigated the acute effects of $10 \mathrm{mg}$ ipsapirone, a $5-\mathrm{HT}_{1 \mathrm{~A}}$ agonist, and $0.5 \mathrm{mg} / \mathrm{kg} \mathrm{m}-\mathrm{CPP}$ (metachlorophenylpiperazine), a 5- $\mathrm{HT}_{2 \mathrm{C}}$ agonist, on cognition and mood in medication-free, young and middle-aged, depressed patients and healthy controls [49]. Ipsapirone tended to improve short-term memory in patients, but impaired short-term memory in controls, whereas neither group showed any ipsapirone-induced changes in mood. M-CPP, on the other hand, impaired performance on reaction time tests in all subjects, and visual search efficiency in patients only. After $\mathrm{m}-\mathrm{CPP}$, depression and tenseness ratings were increased in patients, and increased fatigue was seen in all subjects. The pattern of results seem to indicate that certain transient mood changes may affect certain aspects of performance: increased fatigue was accompanied by increased reaction times, and depression and tenseness were associated with visual search deficiencies. Altered memory functioning, however, appeared to occur without any overt changes in mood states. Moreover, while $5-\mathrm{HT}_{1 \mathrm{~A}}$ agonism impaired memory in healthy subjects, facilitating effects were found in patients. The authors speculate that the latter finding may be related to hippocampal $5-\mathrm{HT}_{1 \mathrm{~A}}$ desensitation in patients [49]. As such, it may be tentatively hypothesized that the differential memory effects may reflect normalization versus overstimulation of hippocampal $5-\mathrm{HT}_{1 \mathrm{~A}}$-mediated serotonergic neurotransmission in patients and healthy subjects, respectively. 


\subsection{Serotonin in Neurodegeneration: Ageing and De- mentia}

Improved understanding of the nature of alterations in the 5-HT system occurring in aging, late-life depression, and dementia has important implications for testing hypotheses of neurochemical mechanisms underlying the aging process and age-related neuropsychiatric disease. Cognitive performance enhancing effects of 5-HT manipulations could be useful in various clinical populations in whom 5-HT function is thought to be compromised. Given the specific involvement of 5-HT in memory consolidation, neurodegenerative diseases may involve the serotonergic system. To consider are ageing, Alzheimer's Disease (AD) and frontotemporal dementia. The working hypothesis is that therapies that stimulate the serotonergic system in these populations might be beneficial.

There is increasing evidence for alterations in the function of the 5-HT system in AD, which may be responsible for many of the behavioural aspects of the disease including the frequent coexistence of depression. The literature implicating 5-HT dysfunction in depression, aging and $\mathrm{AD}$ is based largely on the results of indirect measures, including animal models, post mortem human studies, and peripheral measurements of 5-HT binding [130]. In aging, it has recently been shown that 5-HT2A receptor binding decreases dramatically in a variety of brain regions up through midlife [131]. In AD, 5-HT dysregulation is reported separately or in conjunction with that of the cholinergic system, due to interactions at the receptor level, in particular in septohippocampal cholinergic neurones as well as in cholinergic neurones from the nucleus basalis to the cortex and the amygdala [11]. In a study by Porter [5] AD patients were administered ATD and their cognitive responses were compared to those of age-matched controls. No specific differences were found with respect to cognitive responses to ATD between the AD and control groups. However, the observed effects of ATD both in the normal aged and in the AD groups seemed to differ from those seen in healthy young volunteers. An impairment of performance on the backward digit span was observed after ATD in both groups. Such impairment may well underlie other memory deficits induced by ATD, such as the observed ATDinduced impairment in the Paired Associates Learning test [5]. However, no ATD-induced impairments were found on the Rey auditory verbal learning task and neither on the Rey Visual Design Learning Test. Ultimately, this could mean that memory consolidation impairment, acts as a marker of cognitive aging and although it is a sensitive indicator of ATD, might not be a relevant state marker of 5-HT in AD. Previously, the same group [132] reported on the basis of differences between AD patients and healthy controls in their response to ATD, that using the 3MSE, an extended version of the Mini Mental State Examination scored on a scale of 1-100, AD patients responded to ATD by an impairment of performance on that scale whereas elderly controls did not. Porter et al. [5] noted that this may reflect a ceiling effect on this scale in the elderly control group. We therefore remain with the fact that this was hitherto the first and only study to investigate the specific role of 5-HT in aging and $\mathrm{AD}$.
There are almost no reports of attempts to use SSRIs in $\mathrm{AD}$ and ageing specifically aimed at enhancing cognition. Partly, this is due to the fact that studies of SSRIs in ageing subjects are usually focused on alleviating low mood in latelife depression. In AD, studies of SSRIs have been reported to improve the non-cognitive symptoms rather than cognitive performance [133]. Furthermore, a trial has been reported in which treatment of AD patients with cholinesterase inhibitors was compared to the same in addition with the SSRI citalopram. The outcome focused on attributing additional mood and behavioural symptoms improvement in the cholinesterase inhibitor + SSRI group [134].

Rahman et al. [135] have recently suggested that some of the symptoms associated with the frontal variant of frontotemporal dementia (fvFTD) are related to serotonergic dysfunction. This concerns marked deficits on tests sensitive to ventromedial prefrontal or orbitofrontal function (i.e. risktaking, reversal learning), in the relative absence of impairments on tests sensitive to dorsolateral prefrontal function (i.e. spatial working memory and planning) [135]. Many of the symptoms of fvFTD are indeed currently treated using 5HT-boosting compounds, which are presumably aimed at the aforementioned brain regions and their associated behaviours such as impulsiveness, depression, alterations in eating habits and obsessions and compulsions [136]. Swartz et al. [137] have demonstrated in preliminary studies that it is possible to ameliorate many of these specific symptoms, including impulsivity, depression, carbohydrate craving and compulsions, in fvFTD patients by using 5-HT-boosting compounds [137]. Recently, however, administration of the SSRI paroxetine was found to impair the ability to perform reversal shifts in the ID/ED shift task in patients with frontotemporal dementia [138].

\subsection{Acquired Neurodegeneration: Serotonergic Vulner- ability Associated with MDMA-Use}

Other evidence for cognitive dysfunction associated with putative serotonergic neurodegeneration may come from studies in former users of MDMA. Longlasting degeneration of long serotonergic fibres is seen after MDMA-use in animal studies [139] and may also occur in human users [25, 140, 141]. These indirect observations of potential neurotoxicity are thought to underlie the overtly observed impairments of memory and mood in abstinent MDMA-users. More specifically it has been hypothesised that MDMAusers 'display cognitive deficits in tasks predominantly sensitive to temporal lobe dysfunction', but no deficits in most tasks sensitive to prefrontal functioning [142]. This dissociation might be related to a predominant physiological role of the 5-HT system for mnemonic processes, as has been suggested by neuroanatomy [11] and by ATD studies [2]. However, it may also be related to a particular vulnerability of the hippocampal complex to neurotoxic effects of MDMA [143]. Hence, ATD may be a model of the serotonergic depletion observed after MDMA use. A recent report comparing the metabolic and cognitive responses to ATD of former MDMA users showed that altered 5-HT levels (as manifested by tryptophan levels) as well as impaired memory were the most sensitive markers of ATD's effects in exusers of MDMA [144]. Furthermore, these measures were related in such a way that altered metabolism of tryptophan 
in ex-users may reflect serotonergic vulnerabilty, either due to pre-morbid differences in their 5-HT function or due to acquired drug-induced vulnerability [144].

Treatment options for this group are predominantly antidepressants such as the reuptake inhibitors of 5-HT, as they have been shown to not only elevate 5-HT function, but have also been hypothesised to promote neurogenesis [145, 146]. Besides, estrogen, lithium and rolipram (phosphodiesterase inhibitor) have also been suggested [145].

\subsection{Cognitive Dysfunction as a Marker of Low 5-HT in Diseases Associated with Peripheral Serotonergic Dys- function}

A high proportion of cancer and hepatitis $\mathrm{C}$ patients receiving immune-based therapy with the cytokine interferon-alpha, develops symptoms of depression and comorbid cognitive symptoms such as memory impairment that are indistinguishable from those found in major depressive disorders [147]. The mechanism is poorly understood and could either lead to low 5-HT via reduced appetite due to cytokine treatment or ATD by the cytokine-mediated induction of indoleamine 2,3-dioxygenase (IDO), the enzyme that accelerates the catabolism of tryptophan, or both [147]. Antidepressant treatment could improve these patients' conditions of interleukin-induced depression and memory impairment, by preventing these symptoms to occur and improving compliance with interleukin therapy. The results of a recent placebo-controlled study of preventive SSRI treatment seemed to be largely consistent with this hypothesis [148].

In a different group of cancer patients suffering from carcinoid tumors in the gastrointestinal tract which are known to probably cause a prolonged state of low 5-HT by means of endogenous tryptophan depletion [149], a pattern of cognitive performance was observed that did not resemble that observed in depression, but rather consisted of improved measures of focused attention, similar to the effects of ATD previously described in healthy volunteers [29, 53].

The sensory function of the intestine is highly serotonergically innervated [150]. In patients with irritable bowel syndrome (IBS), 5-HT may play a regulatory role in both gastrointestinal motility and sensitivity, as well as in affective dysregulation [151]. In IBS there is also a hypothesis of endogenous tryptophan depletion and clinical benefits of several serotonergic agents have been shown [152]. Furthermore, it has been reported that greater brain 5-HT synthesis in female IBS patients may be related to the pathological visceral pain processing of the IBS patients, a larger female predominance of the disorder, and the sex difference of the efficacy of the 5-HT3 antagonist in treatment [153]. A recent attempt to show the association of peripheral and central serotonergic dysregulation, has shown that acute lowering of 5-HT synthesis enhances visceral urge and pain perception, while at the same time inducing memory impairment manifested as affective memory bias (i.e. preferential loss of memory for positive emotions), presumably through serotonergic modulation of the 'brain-gut axis' [28]. Treatment of IBS with 5-HT3 antagonists is aimed at improving peripheral serotonergic function. 5-HT3 antagonists have been studied for cognition enhancement, but clinical trials in $\mathrm{AD}$ and mild cognitive impairment have failed.

\section{CONCLUDING REMARKS}

Healthy volunteer studies have provided support, of varying strength, for a role of 5-HT in a number of human cognitive functions. The most robust evidence is available for human episodic memory functions and particularly the detrimental effects of low brain 5-HT on long-term memory consolidation are quite consistently found. At the same time, it must be noted that the experimental data on 5-HT inhibition and human memory are only available from studies using one specific method to lower central 5-HT neurotransmission, namely ATD. The memory deficits that are associated with prolonged MDMA use, presumably caused by MDMA's neurotoxic effects on the 5-HT system, provides indirect corroborating evidence, but currently there are no data on the memory effects of, for example, 5-HT antagonists. Furthermore, it appears to be difficult to ascertain any consistent effects of increased central 5-HT on memory in healthy volunteers. A similar pattern is seen for the notion that 5-HT is involved in focused attention and cognitive flexibility, which is largely based on results of ATD studies, and 5-HT's effect on vigilance, which is solely based on SSRI studies. Overall, the findings of 5-HT modulation of cognition in healthy volunteers are characterized by quite consistent and selective effects of cognitive changes, predominantly performance decrements, following 5-HT manipulations in one direction (inhibition or stimulation), without clear evidence of mirrored behavioral effects of opposite 5-HT manipulations. This may be due to several factors. As mentioned earlier, it may easier to induce performance decrements than to enhance cognitive performance in healthy volunteers who have a close to optimal performance level. Secondly, relatively few 5-HT challenge studies have been performed, using varying pharmacological manipulations, dosages, methods of administration, and treatment regimes, which all can affect the actual level of central 5-HT effects that are achieved, and hence the behavioral outcome of the manipulation. In addition, it is unclear if the relationship between 5-HT activity and cognitive function is a linear one, or instead follows an inverted Ucurve, as has been proposed for frontal DA activity and working memory functions [154]. In latter case, the behavioral effect would be the combined result of baseline 5-HT activity and the level of pharmacological stimulation, with the possibility of performance decrements through overstimulation. At this point, however, there is insufficient data to either support or dismiss an inverted-U curve hypothesis.

While the potential for cognition enhancement by $5-\mathrm{HT}$ drugs in healthy volunteers remains to be established, restoration of impaired cognitive performance due to 5-HT dysfunction is more viable potential target for 5-HT drugs. The observed long-term memory deficits in depression are consistent with the ascribed role of 5-HT in memory formation, and evidence suggest that 5-HT stimulation may have particular beneficial effects on memory in these patients. Yet, a clear evaluation of the cognitive effects of 5-HT antidepressants in most clinical trials is hampered by a lack of control groups. Furthermore, 5-HT drug effects have been almost 
exclusively assessed in a limited subpopulation, namely elderly depressed patients. Also, from the existing data, it is difficult to dissociate the direct effects of 5-HT augmentation on cognition from those that are mediated by alleviation of other symptoms of depression. Comparative studies, assessing the additional value, with regard to cognition, of 5-HT drugs over other effective antidepressant therapies, i.e. non-serotonergic antidepressants and non-pharmacological interventions, would provide further insight into this matter. Low 5-HT has also been implicated in aging, AD and fvFTD, but it is unclear to what extent these serotonergic changes are responsible for the observed cognitive problems. Little work has been done in this area, but evaluation of the cognitive effects of pro-serotonergic drugs in these populations could lead to new fundamental insights in the neurobiology of these conditions, and, if successful, lead to new (co-) treatment strategies and drug development targets for these conditions.

Generally, impaired cognitive function is likely to be the resultant of a set of interacting neurobiological changes, rather than a single factor. Serotonergic dysfunction is unlikely to be the sole cause of cognitive impairment in any condition of illness, but given the mounting evidence of 5HT involvement in variety of cognitive functions, loss of integrity of the central serotonergic system may certainly contribute, in various degrees, to cognitive deterioration. As such, the serotonergic system has become a target for pharmacological cognitive enhancement. The challenge for future research is to seek out those conditions in which low 5HT significantly contributes to cognitive decline. Furthermore, future research aimed at clarifying the nature of the relationship 5-HT and human cognition, identification of the role of 5-HT receptor subtypes, and the potential functional interactions between 5-HT and other neurotransmitter systems that may underlie 5-HT modulation of cognition, would be essential for understanding the full potential of 5HT drugs as cognition enhancers, even in healthy individuals.

\section{ABBREVIATIONS}

5-HT $=5$-hydroxytryptamine
$\mathrm{AD}=$ Alzheimer's Disease
$\mathrm{ATD}=$ Acute Tryptophan Depletion
$\mathrm{CFF}=$ Critical Flicker Fusion
$\mathrm{CNS}=$ Central Nervous System
$\mathrm{DA}=$ Dopamine
DSST $=$ Digit Symbol Substitution Test
EEG $=$ Electroencephalography;
ERP $=$ Event Related Potential;
$\mathrm{fMRI}=$ Functional Magnetic Resonance Imaging;
fvFTD $=$ Frontal Variant of Frontotemporal Dementia
IBS $=$ Irritable Bowel Syndrome
ID/ED $=$ Intra Dimensional/ Extra Dimensional
IDO $=$ Indoleamine 2,3-dioxygenase

MDMA = 3,4-Methylenedioxymethamphetamine, Ecstasy

MEG = Magnetoencephalography

$\mathrm{NA} \quad=$ Noradrenaline

PFC = Prefrontal Cortex

SSRI $=$ Selective Serotonin Reuptake Inhibitor

TCA $=$ Tricyclic Antidepressant

TRP = L-Tryptophan

WCST $=$ Wisconsin Card Sorting Test

\section{REFERENCES}

References 155-157 are related articles recently published in Current Pharmaceutical Design.

[1] Davis KL, Charney D, Coyle JT, Nemerhoff C eds. Neuropsychopharmacology: The Fifth Generation of Progress. American College of Neuropsychopharmacology 2002.

[2] Riedel WJ, Klaassen T, Schmitt JAJ. Tryptophan, mood and cognitive function. Brain Behav Immun 2002; 16: 581-9.

[3] Lai MKP, Tsang SWY, Francis PT, Keene J, Hope T, Esiri MM, et al. Postmortem serotonergic correlated of cognitive decline in Alzheimer's disease. Neuroreport 2002; 13: 1175-8.

[4] Newhouse P, Tatro A, Naylor M, Quealey K, Delgado PL. Alzheimer Disease, serotonin systems and tryptophan depletion. Am J Geriat Psychiat 2002; 10: 483-4.

[5] Porter RJ, Lunn BS, O'Brien JT. Effects of acute tryptophan depletion on cognitive function in Alzheimer's Disease and the healthy ederly. Psychol Med 2003; 33: 41-9.

[6] Richter-Levin G, Segal M. Serotonin, Aging and Cognitive Functions of the Hippocampus. Rev Neurosci 1996; 7: 103-13.

[7] Bethea CL, Lu NZ, Gundlah C, Streicher JM. Diverse actions of ovarian steroids in the serotonin neural system. Front Neuroendocrinol 2002; 23: 41-100.

[8] Roth BL, Hanizavareh SM, Blum AE. Serotonin receptors represent highly favorable molecular targets for cognitive enhancement in schizophrenia and other disorders. Psychopharmacology 2004; 174: 17-24.

[9] Allain H, Bentue Ferrer D, Tribut O, Merienne M, Belliard S. Drug therapy of frontotemporal dementia. Hum psychopharmacol 2003; 18: 221-5

[10] Schmitt JAJ. Serotonin, caffeine and cognition: psychopharmacological studies in human cognitive functioning. Neuropsych Publishers. 2001.

[11] Buhot MC, Martin S, Segu L. Role of serotonin in memory impairment. Ann Med 2000; 32: 210-21.

[12] Buhot M. Serotonin receptors in $\operatorname{cog}$ nitive behaviors. Curr Opin Neurobiol 1997; 7: 243-54.

[13] Meneses A. 5-HT system and cognition. Neurosci Biobehav Rev 1999; 23: 1111-25.

[14] Steckler T, Sahgal A. The role of serotonergic-cholinergic interactions in the mediation of cognitive behaviour. Behav Brain Res 1995; 67: 165-99.

[15] Robbins TW, Granon S, Muir JL, Durantou F, Harrison A, Everitt BJ. Neural systems underlying arousal and attention. Implications for drug abuse. Ann NY Acad Sci 1998; 846: 222-37.

[16] Reilly JG, McTavish SFB, Young AH. Rapid depletion of plasma tryptophan: a review of studies and experimental methodology. J Psychopharmacol 1997; 11: 381-92.

[17] Moore P, Landolt H, Seifritz E, Clark C, Bhatti T, Kelsoe J, et al. Clinical and Physiological Consequences of Rapid Tryptophan Depletion. Neuropsychopharmacology 2000; 23: 601-22.

[18] Nishizawa S, Benkelfat C, Young SN, Leyton M, Mzengeza S, de Montigny $\mathrm{C}$, et al. Differences between males and females in rates of serotonin synthesis in human brain. Proc Natl Acad Sci USA 1997; 94: 5308-13.

[19] Fadda F. Tryptophan-Free Diets: A Physiological Tool to Study Brain Serotonin Function. News Physiol Sci 2000; 15: 260-4.

[20] Young SN, Leyton M. The role of serotonin in human mood and social interaction. Insight from altered tryptophan levels. Pharmacol Biochem Behav 2002; 71: 857-65. 
[21] Young SN. In: Wurtman RJ, Wurtman JJ eds, Nutrition and the Brain. Raven Press 1986; 49-88.

[22] Young SN, Gauthier S. Effect of tryptophan administration on tryptophan, 5- hydroxyindoleacetic acid and indoleacetic acid in human lumbar and cisternal cerebrospinal fluid. J Neurol Neurosurg Psychiat 1981; 44: 323-7.

[23] Young SN. Behavioral Effects of Dietary Neurotransmitter Precursors: Basic and Clinical Aspects. Neurosci Biobehav Rev 1996; 20: $313-23$.

[24] Amado-Boccara I, Gougoulis N, Poirier Littre MF, Galinowski A, Loo H. Effects of Antidepressants on Cognitive Functions: A Review. Neurosci Biobehav Rev 1995; 19: 479-93.

[25] McCann UD, Eligulashvili V, Ricaurte GA. (+/-)3,4Methylenedioxymethamphetamine ('Ecstasy')-Induced Serotonin Neurotoxicity: Clinical Studies. Neuropsychobiology 2000; 42: 11-6.

[26] Green AR, Mechan AO, Elliott JM, O'Shea E, Colado MI. The pharmacology and clinical pharmacology of 3,4-methylenedioxymethamphetamine (MDMA, "ecstasy"). Pharmacol Rev 2003; 55: 463-508

[27] Riedel WJ, Klaassen T, Deutz NEP, Van Someren A, Van Praag HM. Tryptophan Depletion in Normal Volunteers Produces Selective Impairment in Memory Consolidation. Psychopharmacology 1999; 141: 362-9.

[28] Kilkens TOC, Honig A, van Nieuwenhoven MA, Riedel WJ, Brummer RM. Altering serotonin synthesis by the acute tryptophan depletion method: a model for irritable bowel syndrome. Gut 2004; 53: 1794-800.

[29] Schmitt JA, Jorissen BL, Sobczak S, van Boxtel MP, Hogervorst E, Deutz NE, et al. Tryptophan depletion impairs memory consolidation but improves focussed attention in healthy young volunteers. J Psychopharmacol 2000; 14: 21-9.

[30] Harrison BJ, Olver JS, Norman TR, Burrows GD, Wesnes KA Nathan PJ. Selective effects of acute serotonin and catecholamine depletion on memory in healthy women. J Psychopharmacol 2004; 18: 32-40.

[31] Sobczak S, Riedel WJ, Booij L, Aan het Rot M, Deutz NEP, Honig A. Cognition following Acute Tryptophan Depletion: differences between first-degree relatives of bipolar disorder patients and matched healthy control volunteers. Psychol Med 2002; 32: 503-15.

[32] Rowley B, Van F, Mortimore C, Connell J. Effects of Acute Tryptophan Depletion on Tests of Frontal and Temporal Lobe Function. J Psychopharmacol 1998; 12: A60.

[33] McAllister-Williams RH, Massey AE, Rugg MD. Effects of tryptophan depletion on brain potential correlates of episodic memory retrieval. Psychopharmacology 2002; 160: 434-42.

[34] Rubinsztein J, Rogers RD, Riedel WJ, Mehta MA, Robbins TW, Sahakian BJ. Acute dietary tryptophan depletion impairs affective shifting and delayed visual recognition in healthy volunteers. Psychopharmacology 2001; 154: 319-26.

[35] Hughes JH, Gallagher P, Stewart ME, Matthews D, Kelly TP, Young AH. The effects of acute tryptophan depletion on neuropsychological function. J Psychopharmacol 2003; 17: 300-9.

[36] Shansis FM, Busnello JV, Quevedo J, Forster L, Young S, Izquierdo I, et al. Behavioural effects of acute tryptophan depletion in healthy male volunteers. J Psychopharmacol 2000; 14: 15763.

[37] Klaassen T, Riedel WJ, Deutz NEP, Van Someren A, Van Praag HM. Specificity of the tryptophan depletion method. Psychopharmacology 1999; 141: 279-86.

[38] Gallagher P, Massey AE, Young AH, McAllister-Williams RH. Effects of acute tryptophan depletion on executive function in healthy male volunteers. BMC-Psychiat 2003; 3: 10.

[39] Park SB, Coull JT, McShane RH, Young AH, Sahakian BJ, Robbins TW, et al. Tryptophan Depletion in Normal Volunteers Produces Selective Impairments in Learning and Memory. Neuropharmacology 1994; 33: 575-88.

[40] Booij L, van der Does AJW, Riedel WJ. Monoamine depletion in psychiatric and healthy populations: review. Mol Psychiat 2003; 8.

[41] Klaassen T, Riedel WJ, Deutz NEP, Van Praag HM. Mood congruent memory bias induced by tryptophan depletion. Psychol Med 2002; 32: 167-72.

[42] Coffey DK, Jenkyn LR, Coffey AK, Wells BB. Sertraline vs amitriptyline $v s$ placebo: effects on cognitive and motor functioning in the elderly. Neuropsychopharmacology 1994; 10: 222S.
[43] Schmitt JAJ, Kruizinga M, Riedel WJ. Non-serotonergic pharmacological profiles and associated cognitive effects of serotonin reuptake inhibitors. J Psychopharmacol 2001; 15: 173-9.

[44] Siepmann M, Grossmann j, Muck-Weymann M, Kirch W. Effects of sertraline on autonomic and cognitive functions in healthy volunteers. Psychopharmacology 2003; 168: 293-8.

[45] Riedel WJ, Eikmans K, Heldens A, Schmitt JAJ. Specific serotonin reuptake inhibition impairs vigilance performance acutely and after sunchronic treatment. J Psychopharmacol 2005; 19: 1321 .

[46] Sobczak S, Honig A, Schmitt JAJ, Riedel WJ. Pronounced cognitive deficts following an intravenous L-tryptophan challenge in first degree relatives of bipolar patients compared to healthy controls. Neuropsychopharmacology 2003; 28: 711-9.

[47] Harmer CJ, Bhagwagar Z, Cowen PJ, Goodwin GM. Acute administration of citalopram facilitates memory consolidation in healthy volunteers. Psychopharmacology 2002; 163: 106-10.

[48] Furlan PM, Kallan MJ, Ten Have T, Pollock BG, Katz I, Lucki I. The cognitive and psychomotor effects of paroxetine and sertraline on healthy elderly subjects. Am J Geriat Psychiat 2001; 9: 429-38.

[49] Riedel WJ, Klaassen T, Griez E, Honig A, Menheere PP, van Praag HM. Dissociable hormonal, cognitive and mood responses to neuroendocrine challenge: evidence for receptor-specific serotonergic dysregulation in depressed mood. Neuropsychopharmacology 2002; 26: 358-67.

[50] Stroop JR. Studies of interference in serial verbal reactions. J Exp Psychol 1935; 18: 643-62.

[51] Eriksen BA, Eriksen CW. Effects of noise letters upon the identification of a target letter in a nonsearch task. Percept Psychophys 1974; 16: 143-9.

[52] Kimura D, D'Amico C. Evidence for subgroups of adextrals based on speech lateralization and cognitive patterns. Neuropsychologia 1989; 27: 977-86

[53] Coull JT, Sahakian BJ, Middleton HC, Young AH, Park SB, McShane RH, et al. Differential effects of clonidine, haloperidol, diazepam and tryptophan depletion on focused attention and attentional search. Psychopharmacology 1995; 121: 222-30.

[54] Danjou P, Hamon M, Lacomblez L, Warot D. Psychomotor, subjective and neuroendocrine effects of acute tryptophan depletion in the healthy volunteer. Psychiat Psychobiol 1990; 5: 31-8.

[55] Booij L, van der Does AJW, Haffmans JPM, Riedel WJ, Fekkes D, Blom MJB. The effects of high-dose and low-dose tryptophan depletion on mood and cognitive functions of remitted depressed patients. J Psychopharmacol 2005; in press.

[56] Ahveninen J, Kahkonen S, Pennanen S, Liesivuori J, Ilmoniemi RJ, Jaaskelainen IP. Tryptophan depletion effects on EEG and MEG responses suggest serotonergic modulation of auditory involuntary attention in humans. Neuroimage 2002; 16: 1052-61.

[57] Kerr JS, Fairweather DB, Mahendran R, Hindmarch I. The effects of paroxetine, alone and in combination with alcohol on psychomotor performance and cognitive function in the elderly. Int J Psychopharmacol 1992; 7: 101-8.

[58] Schmitt JAJ, Ramaekers JG, Kruizinga M, Van Boxtel MPJ Vuurman EFPM, Riedel WJ. Additional dopamine reuptake inhibition attenuates vigilance decrement induced by serotonergic reuptake inhibition in man. J Psychopharmacol 2002; 16: 207-14.

[59] Hindmarch I, Harrison C. The Effects of Paroxetine and other Antidepressants in Combination with Alcohol in Psychomotor Activity Related to Car Driving. Hum psychopharmacol 1988; 3: 13 20 .

[60] Mackworth NH. In: Sinaiko HW ed, Selected papers on human factors in the design and use of control systems. Dover 1961; 174331.

[61] Ramaekers JG, Muntjewerff ND, O'Hanlon JF. A comparative study of acute and subchronic effects of dothiepin, fluoxetine and placebo on psychomotor and actual driving performance. Br J Clin Pharmacol 1995; 39: 397-404.

[62] Deijen JB, Loriaux SM, Orlebeke JF, De Vries J. Effects of paroxetine and maprotiline on mood, perceptual-motor skills and eye movements in healthy volunteers. J Psychopharmacol 1989; 3: 148-55.

[63] O'Hanlon J, Robbe HWJ, Vermeeren A, VanLeeuwen C, Danjou PE. Venlafaxine's effects on healthy volunteers' driving, psychomotor, and vigilance performance during 15-day fixed and incremental dosing regimens. J Clin Psychopharmacol 1998; 18: 21221 . 
[64] Edgar CJ, Preskorn S, Erickson M, Friesen S, Werder S, Waddington $\mathrm{G}$, et al. A Randomized, double-blind, parallel group comparison of the effects of escitalopram $v s$ sertraline on cognition. J Psychopharmacol 2004; 18: A13.

[65] Delagrange P, Canu MH, Rougeul A, Buser P, Bouyer JJ. Effects of locus coeruleus lesions on vigilance and attentive behaviour in cat. Behav Brain Res 1993; 53: 155-65.

[66] McGaughy J, Sandstrom M, Ruland S, Bruno JP, Sarter M. Lack of effects of lesions of the dorsal noradrenergic bundle on behavioral vigilance. Behav Neurosci 1997; 111: 646-52.

[67] Pribram KH, McGuinness D. Arousal, activation, and effort in the control of attention. Psychol Rev 1975; 82: 116-49.

[68] Robbins TW. Arousal Systems and Attentional Processes. Biol Psychol 1997; 45: 57-71.

[69] Koelega HS. Stimulant drugs and vigilance performance: A review. Psychopharmacology 1993; 111: 1-16.

[70] Matrenza C, Hughes J, Harisson BJ, Kemp A, Wesnes KA, Nathan PJ. Simultaneous depletion of serotonin and catecholamines impairs sustained attention in healthy female subjects without affecting learning and memory. J Psychopharmacol 2003; 18: 2131.

[71] Kerr JS, Sherwood N, Hindmarch I. The comparative psychopharmacology of 5HT reuptake inhibitors. Hum psychopharmacol Clin Exp 1991; 6: 313-7.

[72] Saletu B, Grunberger J. Drug profiling by computed electroencephalography and brain maps, with special consideration of sertraline and its psychometric effects. J Clin Psychiat 1988; 49 Suppl: 59-71.

[73] Raptopoulos P, McClelland GR, Jackson D. The clinical pharmacology of paroxetine in healthy subjects. Acta Psychiat Scand Suppl 1989; 350: 46-8.

[74] McGuirk J, Silverstone T. The effect of the 5-HT re-uptake inhibitor fluoxetine on food intake and body weight in healthy male subjects. Int J Obesity Related Metabol Disord 1990; 14: 361-72.

[75] Schmitt JAJ, Riedel WJ, Vuurman EFPM, Kruizinga M, Ramaekers JG. Modulation of the Critical Flicker Fusion effects of serotonin reuptake inhibitors by concomitant pupillary changes. Psychopharmacology 2002; 160: 381-6.

[76] Mattila MJ, Saarialho-Kere U, Mattila M. Acute effects of sertraline, amitriptyline, and placebo on the psychomotor performance fo healthy subjects over 50 years of age. J Clin Psychiatry 1988; 49: 52-8.

[77] Krawczyk DC. Contributions of the prefrontal cortex to the neural basis of human decision making. Neurosci Biobehav Rev 2002; 26: 631-64.

[78] Cools R, Clark L, Owen AM, Robbins TW. Defining the neural mechanisms of probabilistic reversal learning using event-related functional magnetic resonance imaging. J Neuroscience 2002; 22: 4563-7.

[79] Kringelbach ML, Rolls ET. Neural correlates of rapid reversal learning in a simple model of human social interaction. Neuroimage 2003; 20: 1371-83.

[80] Rogers RD, Owen AM, Middleton HC, Williams EJ, Pickard JD, Sahakian BJ, et al. Choosing between small, likely rewards and large, unlikely rewards activates inferior and orbital prefrontal cortex. J Neuroscience 1999; 19: 9029-38.

[81] Rezai K, Andreasen NC, Alliger R, Cohen G, Swayze V, 2nd, O'Leary DS. The neuropsychology of the prefrontal cortex. Arch Neurol 1993; 50: 636-42.

[82] Volz HP, Gaser C, Hager F, Rzanny R, Mentzel HJ, Kreitschmann-Andermahr I, et al. Brain activation during cognitive stimulation with the Wisconsin Card Sorting Test--a functional MRI study on healthy volunteers and schizophrenics. Psychiat Res 1997; 75: 145-57.

[83] Catafau AM, Parellada E, Lomena F, Bernardo M, Setoain J, Catarineu S, et al. Role of the cingulate gyrus during the Wisconsin Card Sorting Test: a single photon emission computed tomography study in normal volunteers. Psychiat Res 1998; 83: 67-74.

[84] Rogers RD, Tunbridge EM, Bhagwagar Z, Drevets WC, Sahakian BJ, Carter CS. Tryptophan depletion alters the decision-making of healthy volunteers through altered processing of reward cues. Neuropsychopharmacology 2003; 28: 153-62.

[85] Murphy FC, Smith KA, Cowen PJ, Robbins TW, Sahakian BJ. The effects of tryptophan depletion on cognitive and affective processing in healthy volunteers. Psychopharmacology (Berl) 2002; 163: 42-53.
[86] Clark L, Cools R, Robbins TW. The neuropsychology of ventral prefrontal cortex: Decision-making and reversal learning. Brain Cogn 2004; 55: 41-53.

[87] Clarke HF, Dalley JW, Crofts HS, Robbins TW, Roberts AC. Cognitive inflexibility after prefrontal serotonin depletion. $\underline{\text { Science }}$ 2004; 304: 878-80.

[88] Rogers RD, Blackshaw AJ, Middleton HC, Matthews K, Hawtin $\mathrm{K}$, Crowley $\mathrm{C}$, et al. Tryptophan depletion impairs stimulusreward learning while methylphenidate disrupts attentional control in healthy young adults: implications for the monoaminergic basis of impulsive behaviour. Psychopharmacology (Berl) 1999; 146: 482-91.

[89] Evers EAT, Cools R, Clark L, van der Veen FM, Jolles J, Sahakian BJ, et al. Serotonergic modulation of prefrontal cortex during negative feedback in probabilistic reversal learning. Neuropsychopharmacology 2005: 1-10.

[90] Evers EA, Tillie DE, Van Der Veen FM, Lieben CK, Jolles J, Deutz NE, et al. Effects of a novel method of acute tryptophan depletion on plasma tryptophan and cognitive performance in healthy volunteers. Psychopharmacology (Berl) 2004.

[91] Rogers RD, Everitt BJ, Baldacchino A, Blackshaw AJ, Swainson $\mathrm{R}$, Wynne $\mathrm{K}$, et al. Dissociable deficits in the decision-making cognition of chronic amphetamine abusers, opiate abusers, patients with focal damage to prefrontal cortex, and tryptophan-depleted normal volunteers: evidence for monoaminergic mechanisms. Neuropsychopharmacology 1999; 20: 322-39.

[92] Anderson IM, Richell RA, Bradshaw CM. The effect of acute tryptophan depletion on probabilistic choice. J Psychopharmacol 2003; 17: 3-7.

[93] Brand AN, Jolles J, Gispen de Wied C. Recall and recognition memory deficits in depression. J Affect Disord 1992; 25: 77-86.

[94] Zakzanis KK, Leach L, Kaplan E. On the nature and pattern of neurocognitive function in major depressive disorder. Neuropsychiat Neuropsychol Behav Neurol 1998; 11: 111-9.

[95] Den Hartog HM, Derix MM, Van Bemmel AL, Kremer B, Jolles J. Cognitive functioning in young and middle-aged unmedicated outpatients with major depression: testing the effort and cognitive speed hypotheses. Psychol Med 2003; 33: 1443-51.

[96] Austin MP, Mitchell P, Goodwin GM. Cognitive deficits in depression: possible implications for functional neuropathology. $\mathrm{Br} \mathrm{J}$ Psychiat 2001; 178: 200-6.

[97] Burt DB, Zembar MJ, Niederehe G. Depression and memory impairment: a meta-analysis of the association, its pattern, and specificity. Psychol Bull 1995; 117: 285-305.

[98] Purcell R, Maruff P, Kyrios M, Pantelis C. Neuropsychological function in young patients with unipolar major depression. Psychol Med 1997; 27: 1277-85.

[99] Landro NI, Stiles TC, Sletvold H. Neuropsychological function in nonpsychotic unipolar major depression. Neuropsychiatry, Neuropsychiat Neuropsychol Behav Neurol 2001; 14: 233-40.

[100] Murphy FC, Sahakian BJ, Rubinsztein JS, Michael A, Rogers RD, Robbins TW, et al. Decision-making cognition in mania and depression. Psychol Med 2001; 31: 679-693.

[101] Fossati P, Ergis AM, Allilaire JF. Executive functioning in unipolar depression: a review. Encephale 2002; 28: 97-107.

[102] Austin MP, Ross M, Murray C, O'Carroll RE, Ebmeier KP, Goodwin GM. Cognitive function in major depression. J Affect Disord 1992; 25: 21-9.

[103] Elliott R, Sahakian BJ, McKay AP, Herrod JJ, Robbins TW, Paykel ES. Neuropsychological impairments in unipolar depression: the influence of perceived failure on subsequent performance. Psychol Med 1996; 26: 975-89.

[104] Elliott R, Sahakian BJ, Michael A, Paykel ES, Dolan RJ. Abnormal neural response to feedback on planning and guessing tasks in patients with unipolar depression. Psychol Med 1997; 28: 559-71.

[105] Elliott R, Baker SC, Rogers RD, O'Leary DA, Paykel ES, Frith $\mathrm{CD}$, et al. Prefrontal dysfunction in depressed patients performing a complex planning task: a study using positron emission tomography. Psychol Med 1997; 27: 931-42.

[106] Elliott R, Sahakian BJ, Herrod JJ, Robbins TW, Paykel ES. Abnormal response to negative feedback in unipolar depression: evidence for a diagnosis specific impairment. J Neurol Neurosurg Psychiat 1997; 63: 74-82.

[107] Stordal KI, Lundervold AJ, Egeland J, Mykletun A, Asbjornsen A, Landro NI, et al. Impairments across executive functions in recurrent depression. Nordic J Psychiat 2004; 58: 41-7. 
[108] Murphy FC, Michael A, Robbins TW, Sahakian BJ. Neuropsychological impairment in patients with major depressive disorder: the effects of feedback on task performance. Psychol Med 2003; 33: 455-67.

[109] Maes M, Meltzer HY. In: Bloom FE, Kupfer DJ eds, Psychopharmacology: The Fourth Generation of Progress. Raven Press. 1995; 933-44.

[110] Anand A, Charney DS. Norepinephrine dysfunction in depression. J Clin Psychiat 2000; 61 Suppl 10: 16-24.

[111] Ordway GA, Klimek V, Mann JJ. In: Davis KL, Charney D, Coyle JT, Nemeroff C eds, Neuropsychopharmacology the fifth generation of progress. American College of Neuropsychopharmacology. 2002.

[112] Porter RJ, Gallagher P, Watson S, Young AH. Corticosteroidserotonin interactions in depression: a review of the human evidence. Psychopharmacology 2004; 173: 1-17.

[113] Schatzberg AF, Garlow SJ, Nemeroff CB. In: Davis KL, Charney D, Coyle JT, Nemerhoff C eds, Neuropsychopharmacology: The Fifth Generation of Progress. American College of Neuropsychopharmacology 2002.

[114] O'Brien SM, Scott LV, Dinan TG. Cytokines: abnormalities in major depression and implications for pharmacological treatment. Hum Psychopharmacol 2004; 19: 397-403.

[115] Kronfol Z. Immune dysregulation in major depression: a critical review of existing evidence. Int J Neuropsychopharmacol 2002; 5: 333-43.

[116] Richardson JS, Keegan DL, Bowen RC, Blackshaw SL, Cebrian Perez S, Dayal N, et al. Verbal learning by major depressive disorder patients during treatment with fluoxetine or amitriptyline. Int Clin Psychopharmacol 1994; 9: 35-40.

[117] La Pia S, Fuschillo C, Giorgio D, Ciriello R, Pinto A, Rivellini M, et al. Sertonin (5-HT)-related symptoms and fluoxetine in geriatric depression. Arch Gerontol Geriat 2001; 33(Suppl 1): 213-25.

[118] Fairweather DB, Kerr JS, Harrison DA, Moon CA, Hindmarch I. A double blind comparison of the effects of fluoxetine and amitriptyline on cognitive function in elderly depressed patients. Hum Psychopharmacol 1993; 8: 41-7.

[119] Finkel SI, Richter EM, Clary CM. Comparative efficacy and safety of sertraline versus nortriptyline in major depression in patients 70 and older. Int Psychogeriat IPA 1999; 11: 85-99.

[120] Bondareff W, Alpert M, Friedhoff AJ, Richter EM, Clary CM, Batzar E. Comparison of sertraline and nortriptyline in the treatment of major depressive disorder in late life. Am J Psychiat 2000; 157: 729-36.

[121] Doraiswamy PM, Krishnan KR, Oxman T, Jenkyn LR, Coffey DJ, Burt $\mathrm{T}$, et al. Does antidepressant therapy improve cognition in elderly depressed patients? J Gerontol 2003; 58: M1137-44.

[122] Newhouse PA, Krishnan KR, Doraiswamy PM, Richter EM, Batzar ED, Clary CM. A double-blind comparison of sertraline and fluoxetine in depressed elderly outpatients. J Clin Psychiat 2000; 61: 559-68.

[123] Finkel SI, Richter EM, Clary CM, Batzar E. Comparative efficacy of sertraline $v s$. fluoxetine in patients age 70 or over with major depression. Am J Geriat Psychiat Official J Am Assocr Geriat Psychiat 1999; 7: 221-7.

[124] Koetsier GC, Volkers AC, Tulen JH, Passchier J, van den Broek WW, Bruijn JA. CPT performance in major depressive disorder before and after treatment with imipramine or fluvoxamine. J Psychiat Res 2002; 36: 391-7.

[125] Nebes RD, Pollock BG, Houck PR, Butters MA, Mulsant BH, Zmuda MD, et al. Persistence of cognitive impairment in geriatric patients following antidepressant treatment: a randomized, doubleblind clinical trial with nortriptyline and paroxetine. J Psychiat Res 2003; 37: 99-108

[126] Butters MA, Becker JT, Nebes RD, Zmuda MD, Mulsant BH, Pollock BG, et al. Changes in cognitive functioning following treatment of late-life depression. Am J Psychiat 2000; 157: 194954.

[127] Sabbe B, van Hoof J, Hulstijn W, Zitman F. Changes in fine motor retardation in depressed patients treated with fluoxetine. J Affect Disord 1996; 40: 149-57.

[128] Riedel WJ, Schoenmakers E, Vermeeren A, O'Hanlon JF. The Influence of Trazodone Treatment on Cognitive Functions in Outpatients with Major Depressive Disorder. Hum Psychopharmacol 1999; 14: 499-508.
[129] Levkovitz Y, Caftori R, Avital A, Richter Levin G. The SSRIs drug Fluoxetine, but not the noradrenergic tricyclic drug Desipramine, improves memory performance during acute major depression. Brain Res Bull 2002; 58: 345-50.

[130] Meltzer CC, Smith G, DeKosky ST, Pollock BG, Mathis CA, Moore RY, et al. Serotonin in aging, late-life depression and Alzheimer's disease: The emerging role of functional imaging. Neuropsychopharmacology 1998; 18: 407-30.

[131] Sheline YI, Mintun MA, Moerlein SM, Snyder AZ. Greater loss of 5-HT(2A) receptors in midlife than in late life. Am J Psychiat 2002; 159: 430-5.

[132] Porter RJ, Lunn BS, Walker LL, Gray JM, Ballard CG, O'Brien JT. Cognitive deficit induced by acute tryptophan depletion in patients with Alzheimer's disease. Am J Psychiat 2000; 157: 638-40.

[133] Gottfries CG. Late life depression. Eur Arch Psychiat Clin Neurosci 2001; 251(Suppl 2): II57-61.

[134] Moretti R, Torre P, Antonello RM, Cazzato G, Bava A. Depression and Alzheimer's disease: symptom or comorbidity? American J Alzheimer's Disease and Other Dementias 2002; 17: 338-44.

[135] Rahman S, Sahakian BJ, Hodges JR, Rogers RD, Robbins TW. Specific cognitive deficits in mild frontal variant frontotemporal dementia. Brain 1999; 122: 1469-93.

[136] Rahman S, Robbins TW, Sahakian BJ. Comparative cognitive neuropsychological studies of frontal lobe function: implications for therapeutic strategies in frontal variant frontotemporal dementia. Dement Geriat Cognit Disord 1999; 10: 15-28.

[137] Swartz JR, Miller BL, Lesser IM, Darby AL. Frontotemporal dementia: Treatment response to serotonin selective reuptake inhibitors. J Clin Psychiat 1997; 58: 212-6.

[138] Deakin JB RS, Nestor PJ, Hodges JR, Sahakian BJ. Paroxetin does improve symptoms and impairs cognition in frontotemporal dementia: a double-blind randomized controlled trial. Psychopharmacology 2004; 172: 400-8.

[139] Ricaurte GA, Yuan J, McCann UD. (+/-)3,4-Methylenedioxymethamphetamine ('Ecstasy')-Induced Serotonin Neurotoxicity: Studies in Animals. Neuropsychobiology 2000; 42: 5-10.

[140] McCann UD, Szabo Z, Scheffel U, Dannals RF, Ricaurte GA. Positron emission tomographic evidence of toxic effect of MDMA ("Ecstasy") on brain serotonin neurons in human beings. Lancet 1998; 352: 1433-7.

[141] Reneman L, Booij J, Majoie CB, Van Den Brink W, Den Heeten GJ. Investigating the potential neurotoxicity of Ecstasy (MDMA): an imaging approach. Human Psychopharmacol Clin Exp 2001; 16: $579-88$.

[142] Fox HC, McLean A, Turner JJ, Parrott AC, Rogers R, Sahakian BJ. Neuropsychological evidence of a relatively selective profile of temporal dysfunction in drug-free MDMA ("ecstasy") polydrug users. Psychopharmacology 2002; 162: 203-14.

[143] Gouzoulis-Mayfrank E, Thimm B, Rezk M, Hensen G, Daumann J. Memory impairment suggests hippocampal dysfunction in abstinent ecstasy users. Prog Neuropsychopharmacol Biol Psychiat 2003; 27: 819-27

[144] Curran HV, Verheyden SL. Altered response to tryptophan supplementation after long-term abstention from MDMA (ecstasy) is highly correlated with human memory function. Psychopharmacology 2003; 169: 91-103.

[145] Duman RS, Malberg J, Nakagawa S. Regulation of adult neurogenesis by psychotropic drugs and stress. J Pharmacol Exp Therapeut 2001; 299: 401-7.

[146] Jacobs BL, Praag H, Gage FH. Adult brain neurogenesis and psychiatry: a novel theory of depression. Mol Psychiat 2000; 5: 262-9

[147] Capuron L, Hauser P, Hinze-Selch D, Miller AH, Neveu PJ. Treatment of cytokine-induced depression. Brain Behav Immun 2002; 16: 575-80.

[148] Capuron L, Neurauter G, Musselman DL, Lawson DH, Nemeroff $\mathrm{CB}$, Fuchs D, et al. Interferon-alpha-induced changes in tryptophan metabolism. relationship to depression and paroxetine treatment. Biol Psychiat 2003; 54: 906-14.

[149] Russo S, Nielen MM, Boon JC, Kema IP, Willemse PH, De Vries $\mathrm{EG}$, et al. Neuropsychological investigation into the carcinoid syndrome. Psychopharmacology 2003; 168: 324-8.

[150] Camilleri M. Management of the irritable bowel syndrome. Gastroenterology 2001; 120: 652-68.

[151] Kilkens TO, Honig A, Rozendaal N, Van Nieuwenhoven MA, Brummer RJ. Serotonergic modulators in the treatment of irritable 
bowel syndrome - influence on psychiatric and gastrointestinal symptoms. Aliment Pharmacol Therapeut 2003; 17: 43-51.

[152] Lembo T. Neurotransmitter antagonism in management of irritable bowel syndrome. Lancet 2000; 355: 1030-1.

[153] Nakai A, Kumakura Y, Boivin M, Rosa P, Diksic M, D'Souza D, et al. Sex differences of brain serotonin synthesis in patients with irritable bowel syndrome using alpha-[11C]methyl-L-tryptophan, positron emission tomography and statistical parametric mapping. Can J Gastroenterol 2003; 17: 191-6.

[154] Lidow MS, Koh PO, Arnsten AF. D1 dopamine receptors in the mouse prefrontal cortex: Immunocytochemical and cognitive neu- ropharmacological analyses. Synapse New York, NY 2003; 47: 101-8.

[155] Bymaster FP, Lee TC, Knadler MP, Detke MJ, Iyengar S. The dual transporter inhibitor duloxetine: a review of its preclinical pharmacology, pharmacokinetic profile, and clinical results in depression. Curr Pharm Des 2005; 11(12): 1475-93.

[156] Gsell W, Jungkunz G, Riederer P. Functional neurochemistry of Alzheimer's disease. Curr Pharm Des 2004; 10(3): 265-93.

[157] Pacher P, Kecskemeti V. Cardiovascular side effects of new antidepressants and antipsychotics: new drugs, old concerns? Curr Pharm Des 2004; 10(20): 2463-75. 